\title{
Quality Assurance in Endoscopy: Which Parameters?
}

\author{
Ulrike W. Denzer \\ Clinic for Interdisciplinary Endoscopy, University Clinic Hamburg Eppendorf, Hamburg, Germany
}

\author{
Keywords \\ Quality parameters - Gastrointestinal endoscopy · \\ Guideline gastrointestinal endoscopy
}

\section{Summary}

Background: The verbalisation of quality standards and parameters by medical societies are relevant for qualitative improvement but may also be an instrument to demand more resources for health care or be a unique characteristic. Within the health care system 3 different quality levels can be defined: structure, process and result quality. Methods: The current S2k guideline of the German Society for Gastroenterology (quality requirements for gastrointestinal endoscopy) AWMF registry no. 021-022 provides recommendations based on the available evidence for the structure quality (requirements for equipment, human resources) as well as for the process quality (patient preparation, conduct, documentation) and result quality (follow-up of specific endoscopic procedures). Results: Based on these recommendations, measurable quality indicators/parameters for the endoscopy have been selected and formulated. General quality parameters for endoscopic examinations are given as well as quality parameters for specific procedures for the preparation, conduct, and follow-up of specific endoscopic interventions. Conclusion: Only the regular review of processes and courses by means of defined measurement parameters builds up the basis for corrections based on facts. In addition, the implementation of recommended standards may be an instrument in demanding more resources from the health care system and, therefore, should be embedded as routine.

(c) 2016 S. Karger GmbH, Freiburg

\section{Introduction: Quality Concept and Total Quality \\ Management - Development and Meaning in the Health Care System}

Terms such as quality management (QM) and total quality management (TQM) do not primarily evolve in the health care system but rather originate in the industry. These considerations are based on the so-called PIMS (Profit Impact on Market Strategy) study from the 1980s that showed that clients attach more importance to the fulfilment of their requirements concerning the product than to the pure costs. This led to the idea to put the client at the centre of the company and the development, manufacturing, and sales processes. In this context, quality not only refers to the product but also to the complete company and its employees. This requires a strategic business planning of the management [1].

In the 1990s, this quality concept was also transferred to the health care system. It is based on the legal requirement to implement and further develop an internal quality system within the health care system (Code of Social Law, SGB section 135a). The purpose is not only the initially focused systematic improvement of the medical quality but also the improvement of the satisfaction of patients and employees, and, finally, a qualitative improvement, which is relevant for the revenue of the specific medical institution as a whole. The increased demands regarding efficient work resulted in major support for, and advancement of, the implementation of the quality management system within the health care system.

However, the verbalisation of quality standards and parameters by medical societies may also be an instrument in the demand for more resources for the health care (e.g. staff, devices and space) or a unique characteristic. They include for example the quality requirements regarding a certified formation of centres (e.g. intestine centres, pancreatic centres) and the fulfilment of specific quality requirements by measurable, defined quality parameters (e.g. quality assurance agreements for the colonoscopy according to section 135, subsection 2 SGB V for the office-based sector).

\section{KARGER \\ Fax +497614520714

\section{() 2016 S. Karger GmbH, Freiburg}

$2297-4725 / 16 / 0321-0042 \$ 39.50 / 0$
PD Dr. Ulrike Denzer 
Table 1. General quality indicators for the endoscopy [3]

Pre-procedural

Documentation of an adequate indication for the intervention

Timely conducting and documenting the patient information and informed consent

Conducting a standardised risk assessment before the endoscopic intervention Administration of an antibiotic prophylaxis in a given indication

Management of anticoagulating medication before an endoscopic intervention Conducing and documenting a team time out

\section{Intra-procedural}

Photo documentation of landmarks and pathological findings during an endoscopic intervention

Collection and documentation of the duration of an endoscopic intervention (time recording)

Conducting and documenting a continuous vital sign monitoring

Post-procedural

Conducting a standardised discharge management

Compiling complete report documentation

Compiling and documenting follow-up recommendations

Documentation of accessories and instruments

Documentation of intra- and post-procedural complications

Documentation of the frequency of intra- and post-procedural complications (intervention-specific complications) process quality. The process quality includes topics regarding the patient preparation before the endoscopy (information, handling of anticoagulation medication, antibiotic prophylaxis) and recommendations for the preparation, conduct, and follow-up of specific endoscopic procedures and of the documentation.

Based on these recommendations, measurable quality indicators/parameters for the endoscopy have been selected and formulated, and are presented here. Please refer to the corresponding guideline chapters for a detailed justification and statement [3].

\section{General Quality Parameters}

The general quality parameters for endoscopic examinations are summarised in table 1 [3]. The American Society for Gastrointestinal Endoscopy (ASGE) supports the achievement of a quality goal of usually $>98 \%$ with regard to the application of general quality indicators [4]. The German guideline mainly foregoes indicating defined cut-off values, particularly for quality parameters that are generally accepted, legally claimed, and logical (evidence level III; expert opinion) even without any study-based evidence.

\section{Pre-Procedural Quality Parameters}

Quality Levels within the Health Care System: Structure, Process and Result Quality

According to Donabedian [2], 3 different quality levels within the healthcare system can be defined: structure, process and result quality. The structure quality includes the available requirements for patient care pertaining to human resources, premises and techniques. Process quality is related to any processes regarding the treatment of the patients and the organisational and even medical aspects. The result quality derives from the structure and process quality; here, an improvement or worsening of the outcome parameters is documented and reviewed by measurement of target parameters individually formulated for the specific departments.

The parameters of the structure and process quality are normally defined in specifications once and shall be reviewed and updated regulary. The documentation of the quality of results is much more comprehensive as it includes, in case of specific indicator diseases, the continuous registration of the results, e.g. those of the therapeutic endoscopy. This is often only possible with time- and staff-intensive follow-up documentation and patient post-enquiries. Based on the collected facts, it is possible to establish and undertake the required changes regarding the structure and process quality (even in the economic aspect).

The current S2k guideline of the German Society for Gastroenterology 'Qualitätsanforderungen in der gastrointestinalen Endoskopie (Quality requirements for gastrointestinal endoscopy)' AWMF registry no. 021-022 [3] provides recommendations based on the available evidence for the structure quality (premises/requirements for equipment, human resources) as well as for the
Documentation of an Adequate Indication for the Intervention

A documented indication is required for an endoscopic examination or intervention to be performed. The British 'Report of National Confidential Enquiry into Patient Outcome and Death (NCEPOD) - Scoping our Practice' [5] examined 1,818 deaths within 30 days following a therapeutic endoscopy. In $14 \%$ of the patients, the indications were evaluated as inadequate and in $9 \%$ as not indicated. Adequate indications exist if a diagnostic or therapeutic consequence results from the examination or if a therapeutic procedure has primarily been considered. Individual indications can be found in disease-specific guidelines and in the recommendations of the German Society for Gastroenterology, Digestive and Metabolic Diseases (DGVS) [6] and other professional societies [7]. Chapter 4 of the guideline 'Quality Requirements for Gastrointestinal Endoscopy' [3] lists the indications in relation to the specific endoscopic interventions.

\section{Timely Documentation of the Patient Information and Informed Consent}

The German Federal Court of Justice (BGH) states that every medical intervention, even if it is done legally, is a personal injury according to section 223 and subsequent sections of the Criminal Code (StGB). A punishable offence and civil liability can only be omitted if the patient has provided an effective consent. For patients to be able to effectively consent to an intervention while respecting their freedom to make own decisions, they must be informed in detail about the risks related to the medical intervention and be able to consider the principles of the case law [8]. The central function of the informed consent is, therefore, to explain the 
form, meaning, course, and consequences of a planned intervention to the patient and to document this accordingly. Patients must be informed in a timely manner so that they can decide on their own whether the intervention should be performed ([3] chapter 3.1).

\section{Conducting a Standardised Risk Assessment before the}

Endoscopic Intervention

In the scope of the WHO initiative 'Safe surgery saves lives', in 2008 a 19-topic checklist was published providing a 3-level safety check (before the initiation of the anaesthesia, before the incision, and after the completion of the OP) [9]. In 2009, a multicentre study was performed worldwide and examined the efficacy of this WHO checklist [10]. The WHO checklists were used for 3,755 patients before the surgery and for 3,955 patients after the surgery. The complications occurring within a time window of 30 days after the OP were used as an indicator. Using the WHO checklist, it was possible to achieve significant reductions in severe complications, infections, lethality, and mortality in these patients. This can also be transferred to endoscopic interventions, for which the preparation of the patient should also be done by applying a standardised risk assessment identifying the patient's risks related to the intervention and sedation.

\section{Administration of an Antibiotic Prophylaxis in a Given Indication}

The rate of infections with multidrug-resistant pathogens is increasing worldwide. In particular, the increase in resistant intestinal pathogens needs to be mentioned (multi-resistant Gram-negative (MRGN) pathogens). Thus, a moderate, evidence-based use of antibiotics is also required for prophylaxis. However, the bacteraemia rate caused by gastrointestinal endoscopies/interventions is clearly below those caused by daily activities, such as chewing (up to $70 \%$ ) or brushing the teeth (up to $50 \%$ ), without proof of an increased rate for endocarditis or prosthesis infections [11-14]. On the other hand, the administration of an antibiotic ( $\mathrm{AB}$ ) prophylaxis decreases morbidity and mortality for targeted indications and is a measurable parameter. The current guideline ([3] chapter 3.3) provides concrete indication-related recommendations for conducting $\mathrm{AB}$ prophylaxis in the endoscopic field.

\section{Management of an Anticoagulant Medication before an Endoscopic Intervention}

If a patient scheduled for an endoscopic intervention is under medication with anti-platelets and/or oral anticoagulants, it is essential to balance the individual risk of bleeding while performing the endoscopic intervention under the existing medication against the individual risk for a thromboembolic complications by stopping the medication. This also applies for a bridging and renewed administration of the medication. The procedure should also be documented. In difficult individual cases, a consultation with the treating cardiologist/anticoagulation specialist is useful. The current guideline also provides concrete recommendations for the handling of new oral anticoagulants (NOAK) ([3] chapter 3.2).

\section{Conducting and Documenting a Team Time Out}

The team time out (verification process done immediately before starting the procedure) is a useful instrument to prevent an adverse event and complications, and to enable a smooth, target-oriented intervention $[9,10]$. Directly before the endoscopic intervention, details of the patient's risk, preparation, and intervention are queried in a summarised form and documented. The US guidelines on the sedation and care record also mention the team time out as an additional review instrument beyond the pre-endoscopic risk assessment $[15,16]$. An example for the 'Endoscopy team time out form' can also be found in the current guideline ([3] chapter 3.4).

\section{Intra-Procedural Quality Parameters}

Photo Documentation of Landmarks and Pathological Findings during an Endoscopic Intervention

Image documentation needs to be standardised and patient-related. Image documentation should include the following: i) images with 'landmarks' of the examined structures; ii) images of all of the pathological findings; iii) images of all of the therapeutic interventions with documentation from before and after the intervention, optionally also during the intervention. These 3 forms of image documentation are also mentioned in the international guidelines of the ESGE and ASGE as a quality attribute [4, 17]. Furthermore, the image documents should be stored according to the legal requirements and, if applicable, should be submitted to the competent self-governing bodies for quality control reasons [18].

\section{Collection and Documentation of the Duration of an Endoscopic} Intervention (Time Recording)

The time recording of the examination and intervention process includes the time spent for the intervention itself and the time spent on the corresponding preparation and follow-up. The input of time and personnel for each endoscopic intervention should also be shown ([3] chapter 2.3). This has already become a self-evident fact in the surgical field and it is an important basis for adequate imbursement. The time recording of an endoscopic intervention is mentioned in the current guideline as a 'target' recommendation. The time recording programs used should preferably be equipped with a time stamp function (time-based record).

Conducting and Documenting Continuous Vital Sign Monitoring Please refer to the S3 Guideline 'Sedation regarding the Endoscopy' [6].

\section{Post-Procedural Quality Parameters}

\section{Conducting a Standardised Discharge Management}

The German S3 guideline on sedation [6] recommends documenting specific parameters in a structured way before the transfer or discharge of the patients. Corresponding checklists objectively ensure reproducible processes and further support patient safety. 


\section{Compiling Complete Report Documentation}

The completeness of the documentation of medical data is based on the one hand on legal implications $[19,20]$, but is also the basis for a quality control [21]. The documentation of the complete treatment process should include the following aspects:

(1) Patient identification

(2) Examination indication

(3) Identification of examining physician and assistant staff

(4) Device type and identification (serial number)

(5) Medication relating to the documentation requirements according to the $\mathrm{S} 3$ sedation guidelines

(6) Time recording of the examination and intervention process

(7) Completeness and assessability of the examination

(8) Endoscopic findings according to standard classification system (normal result, pathological result)

(9) Endoscopic diagnosis and therapy

(10) Coding of the International Classification of Diseases (ICD) and the Operational and Procedure Key (OPS) by means of stored suggested diagnoses with ICD and OPS code

(11) Documentation of the instruments and materials used

(12) Relevant image files.

\section{Compiling and Documenting Follow-Up Recommendations}

Another important quality attribute is the set of recommendations regarding the follow-up with information on monitoring, transition to a normal diet, possible continuation of anticoagulants, and the further proceeding.

\section{Documentation of Accessories and Instruments}

The documentation of the instruments and materials used and an identification of the disposable material used via barcodes must be performed according to the standard. This ensures a traceable documentation of the materials with respect to the hygiene requirements ([3] chapter 6; [22-24]) and the withdrawal modalities.

\section{Documentation of the Frequency of Intra- and Post-Procedural Complications}

The documentation of intra-procedural complications is an important quality attribute for the intensity of the monitoring and further therapy of the patient, if applicable. The documentation of the frequency of specific intervention-specific complications (intra- and post-procedural) is another quality parameter. To document valid data, an active follow-up of the patient may be required, in particular regarding the documentation of late complications (e.g. telephone contact after an ambulatory polypectomy). Examples for intervention-specific complications are stated in chapter 4 of the guideline [3] under the individual procedures.

\section{Quality Indicators/Parameters for Specific Procedures}

Beyond the general quality parameters (table 1), the quality parameters for specific procedures (supplementary table 1; available at http://content.karger.com/ProdukteDB/produkte.asp?doi=443653) have been derived from the recommendations of the S2k guideline [3] for the preparation, conduct, and follow-up of specific endoscopic interventions.

\section{Oesophagogastroduodenoscopy}

\section{Intra-Procedural}

\section{Complete Oesophagogastroduodenoscopy}

A complete oesophagogastroscopy includes the evaluation of the oesophagus starting from the upper oesophagus sphincter up to the duodenum part II and is a quality attribute [25].

Diagnostic and Follow-Up of Pre-Malignant Lesions in the Oesophagus, Stomach and Duodenum Using High-Solution Video Endoscopy

Most of the studies on the diagnostic work up of pre-malignant lesions in the upper gastrointestinal tract investigated the additional use of contrast enhancement and magnification compared to SD (standard white light) or HD (high definition) endoscopy. Studies using HD endoscopy failed to show a significant benefit for additional chromoendoscopy (real or virtually) in the detection of dysplasia in squamous cell carcinoma and Barrett's oesophagus [26-29]. The current ESGE guideline does not classify the white light endoscopy (SD) as sufficiently exact in differentiating and diagnosing pre-neoplasm conditions and lesions (Helicobacter pylori (HP) gastritis, atrophic gastritis, intestinal metaplasia); thus, the use of the best available endoscopy technique and the collection of sampling biopsies in the endoscopic monitoring are requested for patients with a precancerous condition ([3] chapter 4.1; [30]).

Guideline-Adequate Biopsy Collection from Inflammatory,

Pathological or Pre-Malignant Lesions

Endoscopically suspect lesions include changes of the mucous membrane caused by inflammations, ulcers, tumours, and infections. The diagnostic and monitoring of precancerous conditions relates to Barret's oesophagus but also to the atropic gastritis with or without intestinal metaplasia $[30,31]$. In these cases, the recommendations for the indication and sampling of endoscopic biopsies refer to the current guidelines of the professional society [6].

\section{Endoscopic Treatment of Bleeding from Oesophageal Varices}

\section{Pre-Procedural}

Administration of a Vasopressin Analogue in Acute Variceal Bleeding

Antibiotic Prophylaxis in Acute Variceal Bleeding: The administration of an antibiotic prophylaxis in acute variceal bleeding significantly reduces morbidity and, therefore, should be performed ([3] chapter 3.3). A significant improvement of the initial bleeding control and 5-day haemostasis has been proved for the administra- 
tion of vasopressin analogues in cases of acute variceal haemorrhage ([3] chapter 4.3.2).

\section{Intra-Procedural}

Endoscopic Band Ligation as a First-Choice Procedure for Endoscopic Treatment of Acute Oesophageal Variceal Bleeding and for Endoscopic Primary and Secondary Prophylaxis of Oesophageal Varices

Endoscopic band ligation should preferably be performed in acute oesophageal haemorrhage as the first-choice procedure. Furthermore, band ligation is the first-choice procedure in the endoscopic primary and secondary prophylaxis of oesophageal variceal bleeding ([3] chapter 4.3). For sclerotherapy with Aetoxysklerol/ polidocanol, comparative studies on endoscopic band ligation have shown an increased rate of recurrent bleeding and complications (ulcers, perforation, and mediastinitis) [32-34].

\section{Post-Procedural}

Recommendation to Control and Continue the Endoscopic Band Ligation in the Primary and Secondary Prophylaxis of Oesophageal Varices

The endoscopic band ligation treatment should be periodically performed until eradication. Subsequently, regular endoscopic controls should be undertaken and, if applicable, a renewed ligation therapy if recurrent varices are found. Complete eradication of oesophageal varices with band ligation every $2-4$ weeks is achieved after 2-4 sessions ([3] chapter 4.3 ; [32]).

\section{Endoscopic Therapy of Non-Variceal Bleeding}

\section{Pre-Procedural}

Immediate Proton Pump Inhibitor (PPI) Administration before the Endoscopy if Acute Ulcer Bleeding Is Suspected If acute ulcer bleeding is suspected, therapy with PPI should be administered immediately, independent of the time of the endoscopy. The Cochrane meta-analysis [35] shows the benefits of this procedure with regards to the rate for bleeding stigmata and the number of the required therapeutic interventions ([3] chapter 4.4).

\section{Intra-Procedural}

Performance of a Second Endoscopic Haemostasis Procedure (Mechanical/Thermal) in Addition to Injection Therapy if a High-Risk Stigmata and Peptic Ulcer Bleeding Is Present Several meta-analyses and a Cochrane analysis [36-40] dealing with the endoscopic therapy of peptic ulcer bleeding revealed that the combination with a second haemostasis procedure (haemoclip or thermal procedure) is superior to the injection therapy alone with regards to the recurrent bleeding rate and the requirement to perform surgery ([3] chapter 4.4$)$.

\section{Post-Procedural}

Recommendation of HP Testing and Continuation of a PPI Therapy for Peptic Ulcer Bleeding

In light of the data from a Cochrane analysis [41] and a metaanalysis [42], a high-dose PPI therapy cannot generally be recommended for each case of peptic ulcer bleeding, but it seems to be justified if a high-risk bleeding stigmata is present. If the HP test was not already performed during the acute endoscopy, the report should recommended it be done ([3] chapter 4.4).

\section{Colonoscopy}

\section{Intra-Procedural}

Documentation Rate of the Preparation Quality (Simplified Boston Score)

The Boston Bowel Preparation Scale is the most frequently used validated score $[43,44]$. It defines the cleanliness for 3 sections of the colon with 3 levels $(0=$ not prepared, $1=$ only small parts of the mucosa visible; 2 = mucosa predominantly visible, $3=$ mucosa clearly visible) so that the result is total scores of between 0 and 9 . The quality of the preparation needs to be documented not only for legal reasons. If a bowel is badly prepared, the need for repetition of the colonoscopy has to be discussed with the patient. 2 recent reviews of the literature show that there is no difference of the adenoma detection rate between a very well and well/sufficiently prepared bowel but there are differences between these 2 categories (summarised) and a badly prepared bowel, and they conclude a need for repeated colonoscopies $[45,46]$. If the adenoma detection rate is taken as the main surrogate parameter for the outcome quality of the colonoscopy (as few not-detected carcinomas as possible) [47, 48], this justifies the recommendation that a repeat colonoscopy is necessary in cases of bad bowel preparation ([3] chapter 4.5.1).

Attained Caecum Intubation Rate (Documentation of the Appendix Orifice, Caecum Base and Ileocaecal Valve)

A Canadian database evaluation of 1,260 interval carcinomas revealed that endoscopists with a high caecal rate and those with a higher polypectomy rate (related to account data) detected significantly fewer interval carcinomas and this in an almost linear correlation [49]. The EU guidelines regarding the quality of colorectal carcinoma screenings, including the prophylactic colonoscopy, suggest a cecum intubation rate of at least $90 \%$ as a quality criterion, with the exemption of obstructing processes of the colon [50]. Excluding hindering factors, as the rates vary depending on the adjustment and as it should be assumed that fewer contaminated bowels and strictures can be found during a prophylactic colonoscopy, a rate of $95 \%$ should be supported ([3] chapter 4.5.3). 
Documentation of Withdrawal Time (in the Scope of the Time Recording)

With respect to the withdrawal time, several larger studies showed a positive influence of longer withdrawal times on the adenoma detection rate. Despite being high-level publications, it should be stated that these studies were possibly post-hoc analyses and not prospectively planned studies as there was no prospective time measurement, e.g. with a stopwatch, in cases involving biopsies and polypectomies. For this reason, only negative colonoscopies with no polyp findings requiring a biopsy or resection have been used for the documentation of the withdrawal time ([3] chapter 4.5.23).

\section{Adenoma Detection Rate in Prophylactic Colonoscopy or} Cases with Adequate Indications

A correlation of the adenoma detection rate (ADR, rate for patients with at least 1 adenoma) is plausible despite the limitations of the present studies. For this reason, a cut-off value of $20 \%$ is recommended for the ADR to be achieved in prophylactic colonoscopies [47]. Analysis of the literature shows, in a model calculation for interval carcinomas, a mean rate of 0.7 for non-detected carcinomas; in addition, a rate of 1.1 for the development of a carcinoma due to non-detected carcinomas has been calculated. In contrast, de novo carcinomas not having been detected nor resulting from non-detected carcinomas are evaluated as very rare [51]. It should be explicitly stated that the ADR as a quality parameter is only established for prophylactic colonoscopies, and, thus, it cannot be correlated directly to the diagnostic colonoscopy. According to the available data, symptoms such as abdominal pain (partly termed irritable colon), diarrhoea, and, in particular, constipation show a more or less similar ADR as that of the prophylactic colonoscopy ([3] chapter 4.5.3).

\section{Documentation of the Completeness in Cases of Polypectomy} (Endoscopic Evaluation)

The completeness of the polypectomy should be controlled endoscopically. In this case, the suggested follow-up intervals are given in the recommendations of the DGVS guidelines on colorectal carcinoma $[6,7]$. In the case of a piecemeal resection, biopsies from macroscopically normal scar areas should also be performed during the first endoscopic follow-up. The recommendation for a biopsy even from a normal scar comes from a recently published German 2-centre study in which biopsy specimens of macroscopically inconspicuous scars showed 7\% adenoma tissue at follow-up [52]; however, a recurrence was only seen in $3 \%$ of cases with a normal scar and negative biopsy ([3] chapter 4.5.3; [53]).

\section{Post-Procedural}

Completeness of Performing Histological Examination Following Polypectomy or Biopsy of Non-Ablated Polyps

Resected lesions should be sent for histological examination and the localisation should be indicated. If this is not possible in single cases, this should be documented in the report. The histological evaluation of resected polyps should be considered as standard with regard to the current standard of knowledge. However, in Anglo-American countries, it has been suggested that due to cost reasons $[54,55]$ polyps should be resected but not analysed histologically ('resect and discard', shortly DISCARD). Up to now, this policy is limited to polyps of less than $5 \mathrm{~mm}$ for risk assessment reasons. These considerations are based on several studies of endoscopic differential diagnosis using pit patterns and a virtual chromo-endoscopy, with normally very good results [56-58]. These studies have been summarised in various reviews and 'metaanalyses', such as the recent update of the ASGE recommendation [59]. However, there is an increasing number of high-level studies showing that this does not work in many centres and under 'routine conditions' [60-63].

The uncertainty in differential diagnostic between hyperplastic polyps and sessile serrated adenomas complicates the topic, in particular, with regards to the prognostic meaning. Therefore, the guideline recommends sending resected lesions for histological examination indicating also the localisation.

\section{Endoscopic Retrograde Cholangiopancreatography (ERCP)}

\section{Pre-Procedural}

Post-ERCP Pancreatitis Prophylaxis in Risk Patients/Risk Interventions

The rectal application of $100 \mathrm{mg}$ diclofenac or indomethacin before and after ERCP with papillotomy is well proved for the prophylaxis of a post-ERCP pancreatitis (PEP) and should be applied as standard ([3] chapter 4.8.3).

\section{Intra-Procedural}

Cannulation Success, Successful Stent Placement, Successful Removal of the Stent

Documentation of the Fluoroscopy Time and Dose: A large metaanalysis analysing more than 8,000 publications regarding quality criteria for ERCP included 52 qualitatively adequate prospective and retrospective studies [64]. The cumulative success rate for bile duct cannulation was $89.3 \%$, and that for pancreatic duct cannulation was $85 \%$. A pre-cut was applied in $10.5 \%$. The stone extraction rate from the Ductus hepatocholedochus (DHC) was at $88.3 \%$, and the rate of the successful placement of a stent into the DHC below the hilar bifurcation was $97.5 \%$. The subgroup analysis did not result in statistically significant differences between academic and local endoscopies, and prospective and retrospective studies. There were also no differences for the participation of a trainee during bile duct cannulation, pre-cut, and stone extraction. There were no data available for the pancreatic duct cannulation and bile duct stenting in this setting. The current publication of the ASGE regarding the quality indicators in the ERCP [65] states similar intra-procedural 
quality indicators, whereas here, the success rates for bile duct and pancreatic duct cannulations, DHC stentings, and stone extraction are indicated with $>90 \%$. The documentation of the fluoroscopic time and radiation dose should be performed, and is embedded in the Radiation Protection Act. For further recommendations regarding a standardised procedure in the ERCP, if applicable with derivable quality parameters, please refer to ([3] chapter 4.8.3).

\section{Post-Procedural}

Specific Complications (e.g. PEP, Bleeding after Papillotomy, Perforation)

In addition to the general post-procedural quality indicators, the documentation of specific complications for an ERCP may also serve as a quality indicator. With regard to the documentation of, for example, the PEP, the analysis should be based on the indication of the intervention (planned bile duct or pancreatic duct cannulation, naive versus pre-cut papilla, second intervention following the pre-cut) to define risk subgroups.

\section{Diagnostic Endoscopic Ultrasound}

In 2006 and 2014, a work group of the ASGE and the American College of Gastroenterology published quality indicators for endosonography, including pre-procedural, indication-related procedural and post-procedural criteria $[66,67]$. The specific quality indicators suggested here for endoscopic ultrasound (EUS) and EUSguided fine-needle aspiration (FNA) are based on those suggested by the ASGE [67], and implement the indicators documented in the endosonography registry of the German Society for Ultrasound in Medicine (Deutsche Gesellschaft für Ultraschall in der Medizin; DEGUM) [68].

\section{Pre-Procedural}

Please refer to the general quality parameters for the per-interventional antibiotic prophylaxis in cases of EUS-FNA ([3] chapter $3.3)$.

\section{Intra-Procedural}

Documentation of Anatomic Structures Relevant to the Indication

The indication-related completeness of an examination should be documented by an image or a video sequence and description of the relevant anatomic structures. The description of pathological results requires the indication and documentation of the anatomic localisation, measurements and sonographic structural features (echogenicity, echostructure, contour, relative tissue stiffness, and vascularisation) to enable a clinical and differential diagnostic interpretation, reproducibility, evaluation of therapeutic effects, and follow-up controls. As far as available, internationally accepted classification sys- tems embedded in guidelines should be used. Thus, the description of pathological results using the minimal standard terminology (MST 3.0) for the gastrointestinal endoscopy of the organisation Mondiale D'Endoscopie Digestive (OMED) is useful [69].

\section{EUS-FNA}

\section{Intra-Procedural}

Documentation of the Needle Type, Needle Diameter, Number of Needle Passes, and Material Processing

The description of the results of an EUS-FNA should include information on the target lesion, in case of several target lesions the order of the puncture, the needle route (e.g. trans-oesophageal or trans-gastral), the needle type and diameter, the number of the needle passes, the material quality and processing. This information is, among others, important for the cytopathological diagnosis and for the estimation of the quality of the technical performance. It allows a correlation with the result quality $[66,70]$. All of the mentioned intra-procedural quality indicators are evaluated in the ASGE recommendation [66] with a quality target of $>98 \%$.

\section{Post-Procedural}

\section{Effectiveness of the EUS-FNA}

The portion of malignant diagnoses in cases of EUS-FNA used for solid pancreatic masses was evaluated in a US multicentre study as a surrogate parameter of the diagnostic accuracy suitable for benchmarking. Here, the mean frequency of diagnosed pancreatic carcinomas was $71 \%$ [71]. The authors suggested that a work-up of the complete diagnostic process should be performed if the cytological diagnose rate was $<52 \%$ (1st quartile) [72]. This quality parameter was used by the ASGE [72] but cannot be transferred to the German situation as the indicators for the biopsy of solid pancreatic carcinomas in Germany clearly differ from those used in routine practice in the USA [73]. The percentage of diagnostically adequate material (acceptable: $\geq 85 \%$ ), the portion of conclusive results (diagnostic categories: malignant, neoplasm, benign) and the portion of specific diagnoses with regards to the total number of malignant findings may be used as quality parameters $[72,74,75]$.

\section{Percutaneous Transhepatic Cholangiography and Drainage (PTCD)}

\section{Pre-Procedural}

Conducting an Imaging Procedure of Bile Duct Pre-PTC/ PTCD

Imaging is useful for the indication for, and localisation of, enlarged bile ducts and the planning of a suitable access for the PTC, and, especially, the PTCD [76]. This, in particular, applies to the 
complication rate for this method of $22 \%$ for minor, and $4.7 \%$ for severe complications (mostly bleeding). With more than 3,110 patients, one of the largest case series regarding the complication rates, in particular concerning the arterial vascular injuries, recommended conducting an imaging procedure as a mandatory requirement prior to any new insertion [77].

\section{Intra-Procedural}

\section{PTC/PTCD Success Rate}

The success rate of the PTC is $90 \%$ for cases with dilated bile ducts; for the insertion of a percutaneous drainage in dilated bile ducts success rates between 90 and 100\% can be achieved. The cannulation and drainage of non-dilated bile ducts is more difficult, and related to lower success rates of approximately $70 \%$ ([3] chapter 4.12; $[78,79])$.

\section{Capsule Endoscopy}

\section{Pre-Procedural}

\section{Prevention of Capsule Retention}

Capsule retention is one of the most significant complications (approximately 1-2\%, [80]); it is defined as a capsule remaining in the intestine for more than 14 days. Capsule retentions are more common in some specific diseases or pre-treatments (Crohn's disease $2-3 \%$ in larger series, in some studies partly up to $13 \%$ [ $80-$ 82 ]; tumours of the small intestine $10-25 \%$ [83]). It is possible to prevent retentions in particular in risk groups by imaging or the use of a patency capsule [84].

\section{Intra-Procedural}

Adequate Assessability of the Small Intestine Mucosa

The adequate assessability of the mucosa for the small intestine video capsule endoscopy (VCE) and capsule colonoscopy depends on the preparation [85] and correlates with the diagnostic effect. The preparation regime and the evaluation systems of individual studies vary. Meta-analyses and studies commonly differ between an adequate and inadequate assessability $[86,87]$ and also partly in use of a 4-level evaluation system (excellent, good, moderate, and bad) that is similar to the Aronchick Scale [88].

\section{Complete Small Intestine Capsule Endoscopy (Arrival at the} Caecum during the Examination Time)

A complete small intestine capsule endoscopy is defined as its arrival at the cecum during the examination time [85]. The rate of incomplete examinations is $10-25 \%$ [89]. Due to the longer lifetimes of the current generation of capsules in combination with the real-time viewer, the number of incomplete examinations is now decreasing $[90,91]$.

\section{Disclosure Statement}

The author has no conflict of interests.

\section{References}

1 Pasche F, Schrappe M: Qualtitätsmanagement: Begriffe und Konzept. Med Klin (Munich) 2001;96:497-502.

$\checkmark 2$ Donabedian A: Criteria and standards for quality assessment and monitoring. QRB Qual Rev Bull 1986;12: 99-108.

3 S2k Guideline 'Qualitätsanforderungen in der gastrointestinalen Endoskopie'. www.dgvs.de.

4 Rizk MK, Sawhney MS, Cohen J, et al: Quality indicators common to all GI endoscopic procedures. Gastrointest Endosc. 2015;81:3-16.

5 Cullinane M: Scoping our practice: The 2004 Report of the National Confidential Enquiry into Patient Outcome and Death. London, National Confidential Enquiry into Perioperative Deaths, 2004.

6 Denzer U, Beilenhoff U, Eickhoff A, Faiss S, Hüttl P, In der Smitten S, Jenssen C, Keuchel M, Langer F, Lerch MM, Lynen Jansen P, May A, Menningen R, Moog G, Rösch T, Jakobs R, Rosien U, Vowinkel T, Wehrmann T, Weickert U: S2k-Leitlinie Qualitätsanforderungen in der gastrointestinalen Endoskopie (Kurzversion), AWMF Register Nr. 021-022 Erstauflage 2015. Z Gastroenterol 2015; 53: 1496-1530
7 Denzer U, Beilenhoff U, Eickhoff A, Faiss S, Hüttl P, In der Smitten S, Jenssen C, Keuchel M, Langer F, Lerch MM, Lynen Jansen P, May A, Menningen R, Moog G, Rösch T, Jakobs R, Rosien U, Vowinkel T, Wehrmann T, Weickert U: S2k Leitlinie Qualitätsanforderungen in der gastrointestinalen Endoskopie. AWMF Register Nr. 021-022. Erstauflage 2015. www.awmf.org/leitlinien/ detail/ll/021-022.html (last accessed January 18, 2016).

8 Hüttl P: Aufklärung und Einwilligung; in Heberer J (ed): Arzt und Recht. Berlin, Medizinisch Wissenschaftliche Verlagsgesellschaft, p. 143.

9 World Health Organization: Patient Safety. www.who. int/patientsafety/safesurgery/en/ (last accessed January $18,2016)$.

10 Haynes AB, Weiser TG, Berry WR, et al: A surgical safety checklist to reduce morbidity and mortality in a global population. N Engl J Med 2009;360:491-499.

11 Naber CK, Al-Nawas B, Baumgartner H, et al: Prophylaxe der infektiösen Endokarditis. Kardiologe 2007;1: 243-250.
12 Wilson W, Taubert KA, Gewitz M, et al: Prevention of infective endocarditis: Guidelines from the American Heart Association: a guideline from the American Heart Association Rheumatic Fever, Endocarditis, and Kawasaki Disease Committee, Council on Cardiovascular Disease in the Young, and the Council on Clinical Cardiology, Council on Cardiovascular Surgery and Anesthesia, and the Quality of Care and Outcomes Research Interdisciplinary Working Group. Circulation 2007;116:1736-1754

13 Habib G, Hoen B, Tornos P, et al: ESC Guidelines on the prevention, diagnosis and treatment of infective endocarditis (new version 2009): The Task Force on the Prevention, Diagnosis, and Treatment of Infective Endocarditis of the European Society of Cardiology (ESC). Endorsed by the European Society of Clinical Microbiology and Infectious Diseases (ESCMID) and the International Society of Chemotherapy (ISC) for Infection and cancer. Eur Heart J 2009;30:2369-2413.

14 Allison MC, Sandoe JAT, Tighe R, et al: Antibiotic prophylaxis in gastrointestinal endoscopy. Gut 2009; 58:869-880.

15 Cohen LB, Delegge MH, Aisenberg J: AGA Institute review of endoscopic sedation. Gastroenterology 2007; 133:675-701. 
16 Society of Gastroenterology Nurses and Associates (SGNA): Guidelines for Nursing Documentation in Gastrointestinal Endoscopy 2013. www.sgna.org (last accessed January 18, 2016).

17 Rey JF, Lambert R, ESGE Quality Assurance Committee: ESGE recommendations for quality control in gastrointestinal endoscopy: guidelines for image documentation in upper and lower GI endoscopy. Endoscopy 2001;33:901-903.

18 Empfehlung der Bundesärztekammer zur Qualitätssicherung in der gastrointestinalen Endoskopie. Dtsch Ärztebl 2000;97:A-475-477.

19 Aachen LG, VersR 2001, 1565; OLG Stuttgart, MedR 1995, 320, 323.; 2 vergleiche Clausen, in: Terbille, Münchener Anwaltshandbuch Medizinrecht, $\$ 7$ Rn.47 mwN.; BGH, 20.12.2007, ZR III 144/07 ; OLG Karlsruhe, MedR 1987, 244; BGH, Urteil vom 1. September 1993 - 2 StR 258/93; BGH, Urteil vom 10. März 1993 - 3 StR 461/92; BGH, Urteil vom 21. Mai 1992 - 4 StR 577/91; BGH, Urteil vom 15. Oktober 1991 - 4 StR 420/91, BGH, Beschluss vom 25.01.2012;Az.: 1 StR $45 / 1$

20 Rex DK, Bond JH, Feld AD: Medical-legal risks of incident cancers after clearing colonoscopy. Am J Gastroenterol 2001;96:952-957.

21 Stöltzing H, Birkner B, Lindlar R, et al: Computergestützte Dokumentation bei der oberen gastrointestinalen Endoskopie: Erfahrung bei der Routineanwendung in drei Kliniken. Z Gastroenterol 1989;27:667-675.

22 Empfehlung der Kommission für Krankenhaushygiene und Infektionsprävention (KRINKO) beim Robert Koch-Institut (RKI) und des Bundesinstitutes für Arzneimittel und Medizinprodukte (BfArM). Anforderungen an die Hygiene bei der Aufbereitung von Medizinprodukten. Bundesgesundheitsbl Gesundheitsforsch Gesundheitsschutz 2012;55:1244-1310.

23 Empfehlung der Kommission für Krankenhaushygiene und Infektionsprävention beim Robert Koch-Institut. Anforderungen der Hygiene an die baulich-funktionelle Gestaltung und apparative Ausstattung von Endoskopieeinheiten. Bundesgesundheitsbl Gesundheitsforsch Gesundheitsschutz 2002;45:412-414.

24 Beilenhoff U, Neumann CS, Rey JF, et al: ESGE, ESGENA guideline: Cleaning and disinfection in gastrointestinal endoscopy. Endoscopy 2008;40:939-957.

25 Park WG, Shaheen NJ, Cohen J, et al: Quality indicators for EGD. Gastrointest Endosc 2015;81:17-30.

26 Yokoyama A, Ichimasa K, Ishiguro T, et al: Is it proper to use non-magnified narrow-band imaging for esophageal neoplasia screening? Japanese single-center, prospective study. Dig Endosc 2012;24:412-418.

27 Curvers W, Baak L, Kiesslich R, et al: Chromoendoscopy and narrow-band imaging compared with highresolution magnification endoscopy in Barrett's esophagus. Gastroenterology 2008;134:670-679.

28 Curvers WL, van Vilsteren FG, Baak LC, et al: Endoscopic trimodal imaging versus standard video endoscopy for detection of early Barrett's neoplasia: a multicenter, randomized, crossover study in general practice. Gastrointest Endosc 2011;73:195-203.

29 Singh M, Bansal A, Curvers WL, et al: Observer agreement in the assessment of narrowband imaging system surface patterns in Barrett's esophagus: a multicenter study. Endoscopy 2011;43:745-751.

30 Dinis-Ribeiro M, Areia M, de Vries AC, et al: Management of precancerous conditions and lesions in the stomach (MAPS): guideline from the European Society of Gastrointestinal Endoscopy (ESGE), European Helicobacter Study Group (EHSG), European Society of Pathology (ESP), and the Sociedade Portuguesa de Endoscopia Digestiva (SPED). Endoscopy 2012;44:74-94.
31 Warich-Eitel S, Fischbach W, Eck M: Endoscopic-bioptic diagnostics, surveillance of and therapy for gastrointestinal diseases according to guidelines. Z Gastroenterol 2010;48:414-419.

32 Garcia-Tsao G, Sanyal AJ, Grace ND, et al: AASLD Practice Guideline. Prevention and management of gastroesophageal varices and variceal hemorrhage in cirrhosis. Hepatology 2007;46:922-938.

33 Stiegmann GV, Goff JS, Michaletz-Onody PA, et al: Endoscopic sclerotherapy as compared with endoscopic ligation for bleeding esophageal varices. N Engl J Med 1992;326:1527-1532.

34 Saeed ZA, Stiegmann GV, Ramirez FC, et al: Endoscopic variceal ligation is superior to combined ligation and sclerotherapy for esophageal varices: a multicenter prospective randomized trial. Hepatology 1997; 25:71-74.

35 Leontiadis GI, Sharma VK, Howden CW: Proton pump inhibitor treatment for acute peptic ulcer bleeding. Cochrane Database Syst Rev 2006:CD002094.

36 Laine L, McQuaid KR: Endoscopic therapy for bleeding ulcers: An evidence-based approach based on meta-analyses of randomized controlled trials. Clin Gastroenterol Hepatol 2009;7:33-47; quiz 1-2.

37 Vergara M, Calvet X, Gisbert JP: Epinephrine injection versus epinephrine injection and a second endoscopic method in high risk bleeding ulcers. Cochrane Database Syst Rev 2007:CD005584.

38 Barkun AN, Martel M, Toubouti Y, et al: Endoscopic hemostasis in peptic ulcer bleeding for patients with high-risk lesions: a series of meta-analyses. Gastrointest Endosc 2009;69:786-799.

39 Sung JJ, Tsoi KK, Lai LH, et al: Endoscopic clipping versus injection and thermo-coagulation in the treatment of non-variceal upper gastrointestinal bleeding: a meta-analysis. Gut 2007;56:1364-1373.

40 Marmo R, Rotondano G, Piscopo R, et al: Dual therapy versus monotherapy in the endoscopic treatment of high-risk bleeding ulcers: a meta-analysis of controlled trials. Am J Gastroenterol 2007;102:279-289.

41 Leontiadis GI, Sharma VK, Howden CW: Proton pump inhibitor treatment for acute peptic ulcer bleeding. Cochrane Database Syst. Rev. 2010:CD002094.

42 Wang CH, Ma MH, Chou HC, et al: High-dose vs nonhigh-dose proton pump inhibitors after endoscopic treatment in patients with bleeding peptic ulcer: a systematic review and meta-analysis. Arch Intern Med 2010;170:751-758.

43 Lai EJ, Calderwood AH, Doros G, et al: The Boston bowel preparation scale: a valid and reliable instrument for colonoscopy-oriented research. Gastrointest Endosc 2009;69:620-625.

44 Calderwood AH, Jacobson BC: Comprehensive validation of the Boston Bowel Preparation Scale. Gastrointest Endosc 2010;72:686-692.

45 Clark BT, Rustagi T, Laine L: What level of bowel prep quality requires early repeat colonoscopy: systematic review and meta-analysis of the impact of preparation quality on adenoma detection rate. Am J Gastroenterol. 2014;109:1714-1723; quiz 1724.

46 Jang JY, Chun HJ: Bowel preparations as quality indicators for colonoscopy. World J Gastroenterol 2014;20: 2746-2750.

47 Kaminski MF, Regula J, Kraszewska E, et al: Quality indicators for colonoscopy and the risk of interval cancer. N Engl J Med 2010;362:1795-1803.

48 Regula J, Rupinski M, Kraszewska E, et al: Colonoscopy in colorectal-cancer screening for detection of advanced neoplasia. N Engl J Med 2006;355:18631872.

49 Baxter NN, Sutradhar R, Forbes SS, et al: Analysis of administrative data finds endoscopist quality measures associated with postcolonoscopy colorectal cancer. Gastroenterology 2011;140:65-72.
50 Valori R, Rey JF, Atkin WS, et al.: European guidelines for quality assurance in colorectal cancer screening and diagnosis. First edition - quality assurance in endoscopy in colorectal cancer screening and diagnosis. Endoscopy 2012;44 Suppl 3:Se88-105.

51 Pohl H, Robertson DJ: Colorectal cancers detected after colonoscopy frequently result from missed lesions. Clin Gastroenterol Hepatol 2010;8:858-864.

52 Knabe M, Pohl J, Gerges C, et al: Standardized longterm follow-up after endoscopic resection of large, nonpedunculated colorectal lesions: A prospective two-center study. Am J Gastroenterol 2014;109:183189.

53 Khashab M, Eid E, Rusche M, Rex DK: Incidence and predictors of 'late' recurrences after endoscopic piecemeal resection of large sessile adenomas. Gastrointest Endosc 2009;70:344-349.

54 Hassan C, Pickhardt PJ, Rex DK: A resect and discard strategy would improve cost-effectiveness of colorectal cancer screening. Clin Gastroenterol Hepatol 2010;8: 865-869, 869.e861-863.

55 Kessler WR, Imperiale TF, Klein RW, et al: A quantitative assessment of the risks and cost savings of forgoing histologic examination of diminutive polyps. Endoscopy 2011;43:683-691.

56 Ignjatovic A, East JE, Subramanian V, et al: Narrow band imaging for detection of dysplasia in colitis: a randomized controlled trial. Am J Gastroenterol 2012; 107:885-890.

57 Hassan C, Repici A, Zullo A, et al: Colonic polyps: are we ready to resect and discard? Gastrointest Endosc Clin N Am 2013;23:663-678.

58 Kudo S, Tamura S, Nakajima T, et al: Diagnosis of colorectal tumorous lesions by magnifying endoscopy. Gastrointest Endosc 1996;44:8-14.

59 Abu Dayyeh BK, Thosani N, Konda V, et al: ASGE Technology Committee systematic review and metaanalysis assessing the ASGE PIVI thresholds for adopting real-time endoscopic assessment of the histology of diminutive colorectal polyps. Gastrointest Endosc 2015;81:502.

60 Xie Q, Chen B, Liu L, Gan H: Does the variable-stiffness colonoscope makes colonoscopy easier? A metaanalysis of the efficacy of the variable stiffness colonoscope compared with the standard adult colonoscope. BMC Gastroenterol 2012;12:151.

61 Othman MO, Bradley AG, Choudhary A, et al.: Variable stiffness colonoscope versus regular adult colonoscope: meta-analysis of randomized controlled trials. Endoscopy 2009; 41:17-24.

62 Mark-Christensen A, Brandsborg S, Iversen LH: Magnetic endoscopic imaging as an adjuvant to elective colonoscopy: a systematic review and meta-analysis of randomized controlled trials. Endoscopy 2015;47:251261.

63 Chen Y, Duan YT, Xie Q, et al: Magnetic endoscopic imaging vs standard colonoscopy: meta-analysis of randomized controlled trials. World J Gastroenterol 2013; 19:7197-7204.

64 DeBenedet AT, Elmunzer BJ, McCarthy ST, et al: Intraprocedural quality in endoscopic retrograde cholangiopancreatography: a meta-analysis. Am J Gastroenterol 2013;108:1696-1704.

65 Adler DG, Lieb JG 2nd, Cohen J, et al: Quality indicators for ERCP. Gastrointest Endosc 2015;81:54-66.

66 Wani S, Wallace MB, Cohen J, et al: Quality indicators for EUS. Gastrointest Endosc 2015;81:67-80.

67 Jacobson BC, Chak A, Hoffman B, et al: Quality indicators for endoscopic ultrasonography. Gastrointest Endosc 2006;63(suppl):S35-38.

68 Jenssen C: Diagnostische Endosonografie - State of the Art 2009. Endoskopie Heute 2009;22:89-104. 
69 Aabakken L, Rembacken B, LeMoine O, et al: Minimal standard terminology for gastrointestinal endoscopy MST 3.0. Endoscopy 2009;41:727-728.

70 Jenssen C, Möller K, Wagner S, Sarbia M: Endoscopic ultrasound-guided biopsy: Diagnostic yield, pitfalls, quality management part 1:optimizing specimen collection and diagnostic efficiency. Z Gastroenterol 2008; 46:590-600

71 Savides TJ, Donohue M, Hunt G, et al: EUS-guided FNA diagnostic yield of malignancy in solid pancreatic masses: a benchmark for quality performance measurement. Gastrointest Endosc 2007;66:277-282.

72 Wani S, Muthusamy VR, Komanduri S: EUS-guided tissue acquisition: An evidence-based approach (with videos). Gastrointest Endosc 2014;80:939-959 e937.

73 Adler G, Seufferlein T, Bischoff SC, et al.: S3-Guidelines 'Exocrine pancreatic cancer' 2007 (in German). Z Gastroenterol 2007;45:487-523.

74 Skov BG, Baandrup U, Jakobsen GK, et al: Cytopathologic diagnoses of fine-needle aspirations from endoscopic ultrasound of the mediastinum: reproducibility of the diagnoses and representativeness of aspirates from lymph nodes. Cancer 2007;111:234-241.

75 Eltoum IA, Chhieng DC, Jhala D, et al: Cumulative sum procedure in evaluation of EUS-guided FNA cytology: the learning curve and diagnostic performance beyond sensitivity and specificity. Cytopathology 2007; 18:143-150

76 Practise guidelines for specifications and performance of image guided percutaneous drainage / aspiration of abscesses and fluid collections. Am Coll Radiol 2014 www.acr.org/ /media/ACR/Documents/PGTS/guidelines/PDAFC.pdf (last accessed January 21, 2016).
Choi SH, Gwon DI, Ko GY, et al: Hepatic arterial injuries in 3110 patients following percutaneous transhepatic biliary drainage. Radiology 2011;261:969-975.

78 Weber A, Gaa J, Rosca B, et al: Complications of percutaneous transhepatic biliary drainage in patients with dilated and nondilated intrahepatic bile ducts. Eur J Radiol 2009;72:412-417.

79 Saad WE, Wallace MJ, Wojak JC, et al: Quality improvement guidelines for percutaneous transhepatic cholangiography, biliary drainage, and percutaneous cholecystostomy. J Vasc Interv Radiol 2010;21:789795.

80 Liao Z, Gao R, Xu C, Li ZS: Indications and detection, completion, and retention rates of small-bowel capsule endoscopy: a systematic review. Gastrointest Endosc 2010;71:280-286.

81 Cheifetz AS, Lewis BS: Capsule endoscopy retention: is it a complication? J Clin Gastroenterol 2006;40:688691.

82 Li F, Gurudu SR, De Petris G, et al: Retention of the capsule endoscope: a single-center experience of 1000 capsule endoscopy procedures. Gastrointest Endosc 2008;68:174-180.

83 Pennazio M, Rondonotti E, de Franchis R: Capsule endoscopy in neoplastic diseases. World J Gastroenterol 2008;14:5245-5253.

84 Herrerias JM, Leighton JA, Costamagna G, et al: Agile patency system eliminates risk of capsule retention in patients with known intestinal strictures who undergo capsule endoscopy. Gastrointest Endosc 2008;67:902909.
85 May A, Albert J, Keuchel M, et al: Capsule endoscopy for the diagnosis of small bowel diseases. An updated statement by the endoscopy section of DGVS. Z Gastroenterol 2010;48:1384-1404

6 Belsey J, Crosta C, Epstein O, et al: Meta-analysis: Efficacy of small bowel preparation for small bowel video capsule endoscopy. Curr Med Res Opin 2012;28:18831890

87 Rokkas T, Papaxoinis K, Triantafyllou K, et al: Does purgative preparation influence the diagnostic yield of small bowel video capsule endoscopy? A meta-analysis. Am J Gastroenterol 2009;104:219-227.

88 Aronchick CA: Bowel preparation scale. Gastrointest Endosc 2004;60:1037-1038; author reply 8-9.

89 Zhang JS, Ye LP, Zhang JL, et al: Intramuscular injection of metoclopramide decreases the gastric transit time and does not increase the complete examination rate of capsule endoscopy: a prospective randomized controlled trial. Hepatogastroenterology 2011;58: 1618-1621.

90 Park JY, Kim HM, Choi YA, et al: Longer capsule endoscopy operation time increases the rate of complete examination of the small bowel. Hepatogastroenterology 2010;57:746-750

91 Shiotani A, Honda K, Kawakami M, et al.: Use of an external real-time image viewer coupled with prespecified actions enhanced the complete examinations for capsule endoscopy. J Gastroenterol Hepatol 2011;26: 1270-1274. 